\title{
APLICAÇÃO DO SISTEMA COMPUTACIONAL SAPEVOWEB NA SELEÇÃO DE FORNECEDORES DE TOTENS DE AUTOATENDIMENTO EM BASES DE DISTRIBUIÇÃO DE COMBUSTÍVEIS
}

\author{
Rafael Ferreira Almeida (INSTITUTO MILITAR DE ENGENHARIA) \\ rafaelfalme@yahoo.com.br \\ Ana Lívia Alves Caitano (INSTITUTO MILITAR DE ENGENHARIA) \\ livia.alvescaitano@gmail.com \\ Paulo Afonso Lopes (INSTITUTO MILITAR DE ENGENHARIA) \\ pauloafonsolopes@uol.com.br
}

Prof. Dr. Marcos dos Santos, Orientador (INSTITUTO MILITAR DE ENGENHARIA)

marcosdossantos_doutorado@yahoo.com.br

\section{Resumo}

Resumo: Em uma base de distribuição de combustíveis, as atividades de faturamento do pedido são realizadas pela equipe de apoio logístico, antes do caminhão-tanque entrar no pátio de carregamento. Devido ao alto volume de operações realizadas diariamente, são necessários 180 profissionais para execução destas atividades nas 41 unidades operacionais da empresa estudada. Face a possibilidade de automatização deste processo através da utilização de totens de autoatendimento, foi realizado uma pesquisa no mercado para identificar os fornecedores que possuem capacidade de atender à especificação técnica necessária e foi utilizado o método SAPEVO-M para auxílio à tomada de decisão sobre qual a melhor alternativa, baseado nos critérios de aquisição utilizados pela empresa e no julgamento de 3 especialistas da área operacional. Após aplicação do método, utilizando o aplicativo computacional SapevoWeb, os 3 fornecedores habilitados foram ranqueados a partir dos pesos gerados para cada critério e análise dos especialistas, sendo escolhido o fornecedor que apresentou a maior pontuação, gerando uma análise imparcial e contribuindo para um processo de compras mais eficiente e assertivo.

Palavras-chave: Autoatendimento; Sistema SapevoWeb; Método SAPEVO-M; Distribuidora de Combustíveis. 


\section{Introdução}

Segundo a Agência Nacional do Petróleo (2019), a revenda de combustíveis no Brasil é um mercado extenso, com aproximadamente 99.000 agentes reguladores, responsáveis pela venda a varejo de combustíveis automotivos, de aviação e GLP, o que torna o mercado de distribuição muito competitivo.

Segundo Cardoso (2004), a atividade de distribuição de combustíveis engloba mais do que apenas a comercialização e entrega, mas também está relacionada à aquisição, armazenagem, transporte e controle de qualidade dos combustíveis líquidos derivados de petróleo, álcool combustível, lubrificantes, gás liquefeito envazado e outros combustíveis automotivos.

Em um país de dimensões continentais, um grande desafio logístico é atender as regiões longínquas, garantindo a qualidade dos produtos e competitividade nos preços. Para isso, as distribuidoras possuem bases estrategicamente localizadas em diversas regiões do país, para receber os produtos de refinarias, usinas ou importação e viabilizar o atendimento ao mercado (CARDOSO, 2004).

Um grande desafio para as distribuidoras de combustíveis está relacionado à capacidade de suas bases atenderem à toda demanda do mercado, com eficiência e segurança. Para isso, são necessários investimentos em equipamentos, instalações e ampliação da capacidade de carregamento, que devem ser precedidos de estudos de viabilidade, porque quaisquer alterações na estrutura física de uma unidade operacional incorrem em altos custos, sendo o retorno computado apenas no longo prazo.

Para auxiliar nestes estudos de viabilidade e auxílio à tomada de decisão, são utilizadas técnicas de Pesquisa Operacional (PO) que, segundo Pizzolato e Gandolpho (2009), a PO é um conjunto de técnicas e ferramentas para resolver problemas complexos que desafiam a criatividade humana, porque faz uso de métodos quantitativos para o gerenciamento de sistemas e a tomada de decisão.

Algumas das técnicas que compõem e auxiliam a formular a melhor solução possível são a simulação, otimização e auxílio multicritério à decisão, por exemplo, que podem ser ramificadas entre analíticas e computacionais, sendo aplicadas de acordo com a necessidade de cada problema e da quantidade e disponibilidade de dados. As inserções da pesquisa operacional, principalmente do auxílio multicritério à decisão, através de ferramentas 
computacionais, ocasionam mudanças constantes na maneira como são executados os processos de escolhas das melhores alternativas em um problema, a fim de obter decisões mais assertivas e com menos vieses.

O auxílio multicritério à decisão é geralmente utilizado quando o gestor utiliza vários critérios conflitantes. O método SAPEVO-M (Simple Aggregation of Preferences Expressed by Ordinal Vectors - Multi decision makers) envolve variáveis qualitativas para quantificar e validar a opinião dos especialistas, através da normalização de matrizes de decisão. Representa uma nova versão do método ordinal SAPEVO (Gomes, Mury e Gomes, 1997) possibilitando sua aplicação por mais de um tomador de decisão.

Considerando a relevância do tema abordado por este trabalho, o presente artigo tem como problema de pesquisa a aplicação do método SAPEVO-M, através do sistema computacional SapevoWeb, para auxiliar à tomada de decisão sobre a escolha da melhor alternativa de fornecedor para totens de autoatendimento em bases de distribuição de combustíveis. Tal questionamento há de requerer tanto uma breve revisão bibliográfica do método, quanto a utilização de julgamentos de especialistas combinados com a pesquisa de mercado realizada sobre a capacidade técnica dos potenciais fornecedores e das informações sobre os critérios analisados, afim de permitir que a temática investigada atinja o objetivo geral da pesquisa, que é ordenar os fornecedores pelo maior vetor resultante da combinação dos pesos dos critérios com a avaliação das alternativas, para determinar o melhor fornecedor de totens de autoatendimento no processo de faturamento em bases de distribuição de combustíveis.

\section{Auxílio Multicritério à Decisão}

\subsection{Considerações Gerais}

O auxílio multicritério à decisão possibilita a tomada de decisões a partir da análise de vários critérios, podendo os mesmos ser conflitantes entre si, porque representa um conjunto de técnicas e métodos para apoiar ao decisor a considerar a relevância desses critérios no processo decisório (OLIVEIRA, CORREIA e MELLO., 2008).

Gomes, Gonzalez-Araya e Carignano (2004) descrevem o processo de auxílio multicritério à decisão em 9 etapas, quais sejam a identificação dos tomadores de decisão e seus objetivos, a definição das alternativas do problema, dos critérios a serem analisados, avaliação das alternativas considerando os critérios selecionados, definição dos pesos dos critérios, 
avaliação de cada uma das alternativas em relação às demais, realização de análise de sensibilidade, proposta de solução e implantação das ações para viabilizar a alternativa escolhida.

Segundo Caitano et al. (2019), quando há divergências entre os decisores, estas metodologias multicritério formam uma estrutura sólida para discussões, permitindo uma melhor percepção do problema.

Para apoiar os decisores no processo de tomada de decisões envolvendo problemas complexos, tem-se utilizado o auxílio multicritério à decisão, a partir da seleção, avaliação e ordenação das alternativas dos problemas, através de critérios qualitativos e quantitativos selecionados para análise dos cenários (GOMES e GOMES, 2019).

Uma decisão visa atingir o melhor resultado com os recursos disponíveis. Cabe aos decisores o papel de identificação e seleção das melhores ferramentas para apoiar a estruturação do processo decisório, que pode considerar aspectos técnicos, econômicos, sociais e ambientais para análise das alternativas de solução do problema, em todos os níveis organizacionais (GRECO, FIGUEIRA e EHRGOTT, 2016).

\subsection{Método SAPEVO-M}

O método Simple Aggregation of Preferences Expressed by Ordinal Vectors - Multi Decision Makers (SAPEVO-M) foi proposto por Gomes e Santos em 2018, a partir da revisão do método SAPEVO, proposto por Gomes e Gomes em 1997, tendo como contribuições a possibilidade da tomada de decisão poder ser realizada por vários decisores e o aumento da consistência matemática do método ao incluir um processo de normalização das matrizes de decisão.

Segundo Teixeira, Santos e Gomes (2019), o método SAPEVO-M é desenvolvido por meio de 2 processos, sendo o primeiro referente à geração de um vetor representativo dos pesos dos critérios selecionados, a partir da transformação ordinal da preferência entre esses critérios. Já o segundo processo está relacionado à transformação ordinal da preferência das alternativas por cada um dos decisores, a partir dos mesmos critérios, para geração de uma matriz de avaliação. O ranking das alternativas será elaborado a partir dos resultados do vetor resultante da multiplicação desta matriz de avaliação com o vetor peso. 
Para gerar os pesos dos critérios, estes são comparados em pares por cada um dos decisores. E para gerar as preferências, cada decisor realiza uma comparação pareada entre as alternativas para cada um dos critérios selecionados, levando em consideração a métrica disposta na tabela 1.

Tabela 1 - Escala de importância

\begin{tabular}{|cc|}
\hline Expressão Linguística & Pontuação \\
\hline Absolutamente Pior / Absolutamente Menos Importante & -3 \\
\hline Muito Pior / muito Menos Importante & -2 \\
\hline Pior / Menos Importante & -1 \\
\hline Igual ou Equivalente / tão importante quanto & 0 \\
\hline Melhor / Mais Importante & 1 \\
\hline Muito Melhor / muito Mais Importante & 2 \\
\hline Absolutamente Melhor / absolutamente Mais Importante & 3 \\
\hline
\end{tabular}

Fonte: www.sapevoweb.com

Teixeira, Santos e Gomes (2019) descrevem que a partir da matriz de avaliação gerada pelos decisores, o método SAPEVO-M prevê a normalização do vetor resultante, garantindo a geração de valores não negativos, através da equação:

$$
\text { v }=[(\text { aij }- \text { Mín aij) / (Máx aij - Mín aij) }]
$$

Como não faz sentido um critério possuir peso nulo, no momento da normalização dos critérios, os menores valores de seus pesos são substituídos por $1 \%$ do próximo valor.

\subsection{Sistema Computacional SapevoWeb}

A ferramenta SapevoWeb foi desenvolvida na linguagem Python, através da utilização do framework Django e HTML, em uma parceria entre o Centro de Análise de Sistemas Navais (CASNAV), o Instituto Militar de Engenharia (IME) e a Universidade Federal Fluminense (UFF). Pode ser considerada uma ferramenta bastante intuitiva para aplicação do método de auxílio multicritério com vários decisores SAPEVO-M, devido sua plataforma de fácil acesso e interatividade com os usuários (TEIXEIRA, SANTOS e GOMES, 2019). 
O acesso ao SapevoWeb pode ser realizado gratuitamente pelo seguinte endereço eletrônico www.sapevoweb.com, cuja tela inicial está apresentada na Figura 1.

Figura 1 - Tela inicial da ferramenta SapevoWeb

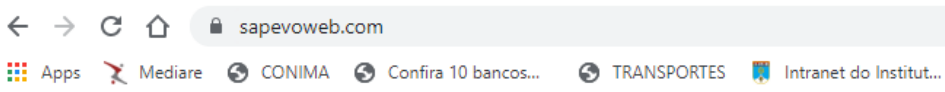

\section{SapevoWeb}

SAPEVO-M:Simple Aggregation of Preferences Expressed by Ordinal Vectors - Mutiti Decision Makers

\section{Cadastrar Projeto}

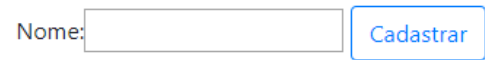

Fonte: www.sapevoweb.com

\section{Estudo de caso}

\subsection{Bases de distribuição de combustíveis}

A matriz energética brasileira apresenta um consumo de $36,4 \%$ de petróleo e derivados e o mercado brasileiro de transportes apresentou aumento de 1,5\% nas vendas de combustíveis no comparativo de 2018 com 2017 (ANP,2019).

A PLURAL (2019) estima que o mercado brasileiro possua 270 bases de distribuição de combustíveis instaladas no território nacional, conforme representado na Figura 2, responsáveis pela armazenagem e movimentação média anual de $14.600 .000 \mathrm{~m}^{3}$ de gasolina e diesel importados e 412.000.000 de barris de gasolina e diesel produzidos. 
Figura 2 - Mapa das bases de distribuição de combustíveis no Brasil
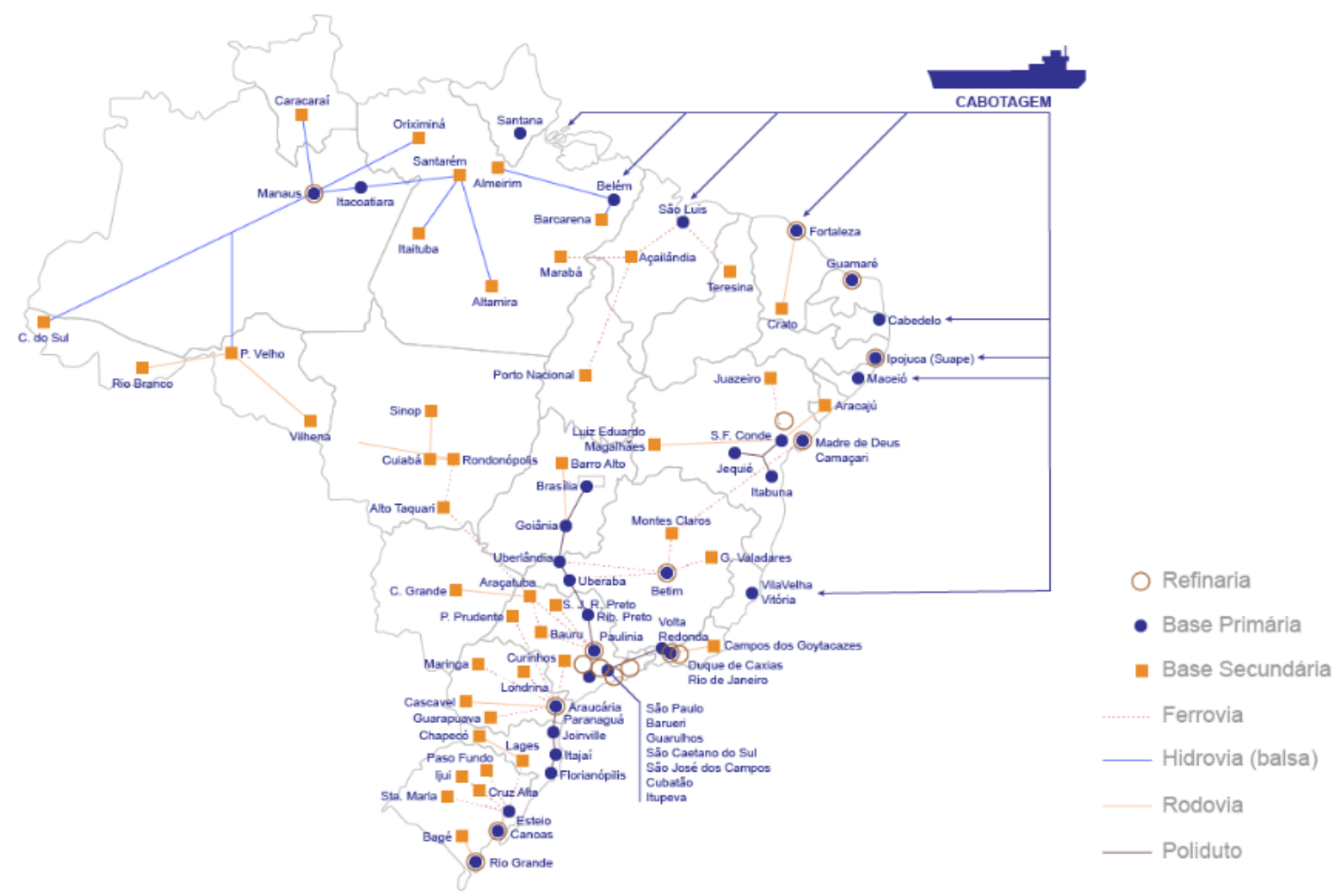

Fonte: www.somosplural.com.br

Ainda segundo a PLURAL (2019), há uma expectativa de crescimento no consumo de combustíveis devido à retomada econômica do Brasil prevista para 2020, após consolidação do conceito de liberdade de preços, estabilidade regulatória e previsibilidade nas regras ao mercado, porque o Brasil espera atrair investimentos privados na ordem de $\mathrm{R} \$$ 17.000.000.000,00 em ampliação de capacidade logística relacionada à infraestrutura de importação e distribuição de combustíveis.

A base de distribuição é considerada uma área estratégica da cadeia de suprimentos de combustíveis devido aos seguintes aspectos:

a) complexidade de sua operação;

b) importância de sua localização nos custos logísticos;

c) ideal configuração operacional para realização das atividades de recebimento por diversos modais, armazenagem em seus tanques, mistura dos aditivos e bioderivados;

d) processo de carregamento dos caminhões-tanque; e

e) abastecimento dos combustíveis nos postos de serviço e grandes consumidores. 
A figura 3 abaixo ilustra um modelo de cadeia de suprimentos de combustíveis, destacando as bases de distribuição, que são responsáveis pela integração dos elos desta cadeia.

Figura 3 - Cadeia de Suprimentos de Combustíveis

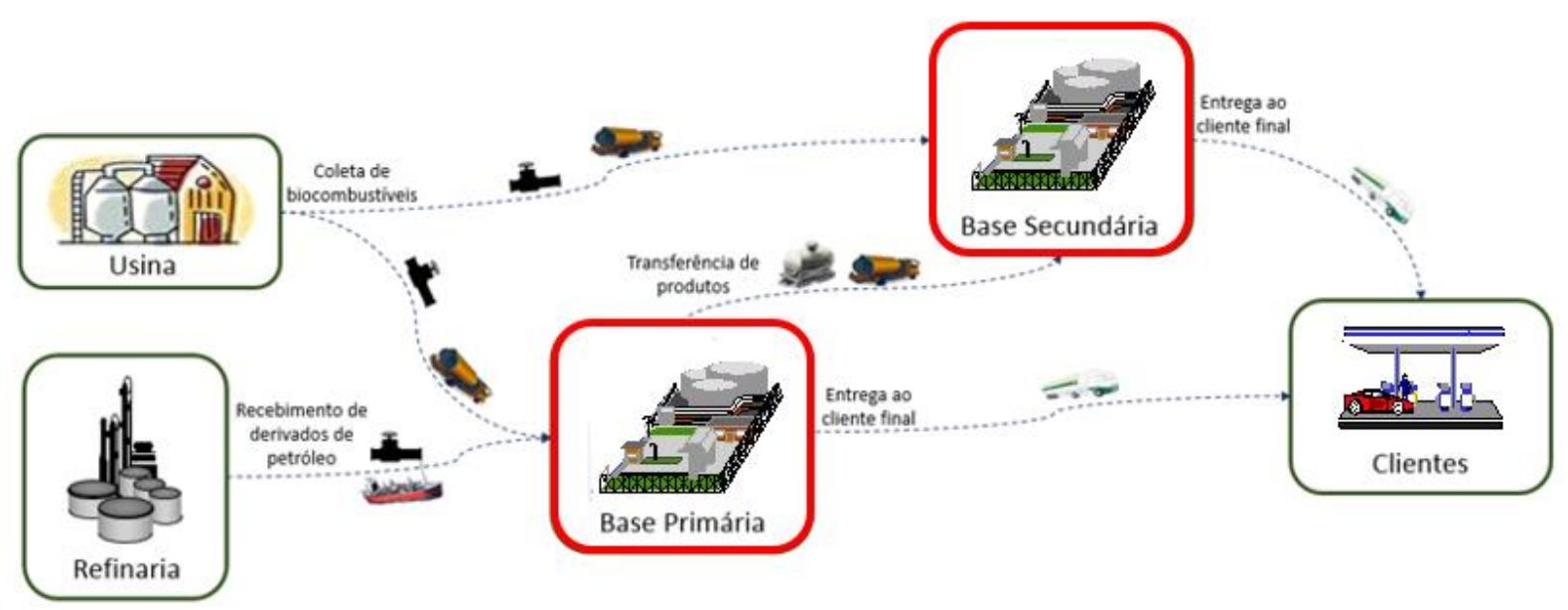

Fonte: Autores (2020)

Devido à importância da base para o abastecimento de combustíveis aos clientes finais e varejo (rede de postos), é necessário desenvolver melhorias e automatizações nos processos de faturamento e carregamento, para atendimento à demanda do mercado prestando melhor nível de serviço que os concorrentes, a fim de melhorar o atendimento, o relacionamento e ampliar a participação de mercado.

\subsection{Processo de faturamento}

O motorista, após realizar a passagem pela portaria de Entrada no Pátio Externo (EPE), estaciona o caminhão-tanque (CT) no pátio externo, segue para a sala de espera dos motoristas para realizar a entrada na base (EB), quando passa o cartão de identificação do CT na unidade de controle de acesso (UCA) apropriada, retira a ordem de carregamento (OC), imprime o comprovante do auto check-list e/ou análise prévia de risco de viagem e os entrega ao colaborador do apoio logístico, conforme mostra a Figura 4.

Após esta etapa do processo, o colaborador do apoio logístico confere as informações apresentadas e, após confirmação de regularidade no processo, insere as numerações dos lacres e envelopes no sistema, quando necessário. Após consolidação dos dados pela Secretaria da Fazenda (SEFAZ), o apoio logístico entrega as notas fiscais (NF) ao motorista que aguarda na sala de espera até que o sistema integrado de gestão (SIG) disponibilize vaga 
nas baias da plataforma de carregamento de CT e direcione o motorista, através do Monitor de Chamada com a mensagem "Entrada Imediata" para iniciar o carregamento no pátio interno (EPI).

Figura 4 - Motorista retirando documentação no Apoio Logístico

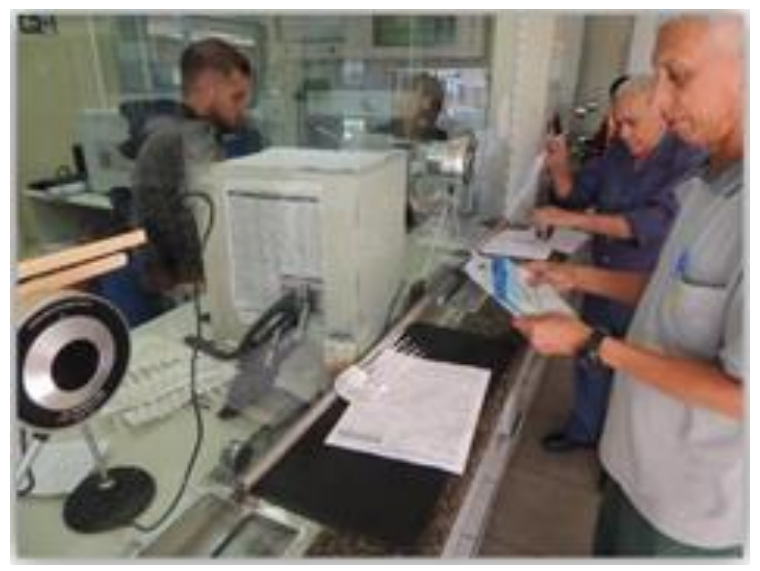

Fonte: Autores (2020)

Os lacres são entregues para todos os carregamentos, diferente dos envelopes, que são entregues para os casos em que deverá ser coletada amostra testemunho de produtos na plataforma de carregamento de CT (conforme resolução ANP44/2013) e os vale-pedágios são entregues para os transportadores, sendo todos estes casos parametrizados nos sistemas corporativos.

Os comprovantes de entregas são levados junto com os documentos auxiliares da nota fiscal eletrônica (DANFE) pelos motoristas nos casos de entregas pelas transportadoras, sendo assinados pelos motoristas, devidamente identificados na nota fiscal e devolvidos ao colaborador do apoio logístico nos casos de entregas com CT próprios. Para as transferências de combustíveis entre bases não há comprovante de entrega, pois a confirmação de entrega é realizada automaticamente após o recebimento pela unidade de destino.

As notas fiscais são emitidas automaticamente, conforme sequências lógicas dos sistemas corporativos de gestão. Já a emissão do vale-pedágio é feita automaticamente e realizada imediatamente após a emissão da nota fiscal, sendo a entrega realizada junto com a nota fiscal. 
A Figura 5 apresenta o fluxograma do processo de faturamento de pedido em bases de distribuição de combustíveis e seu desdobramento até a entrada no pátio interno, para carregamento do CT.

Figura 5 - Fluxograma do processo entre o EPE e EPI, sem totem de autoatendimento

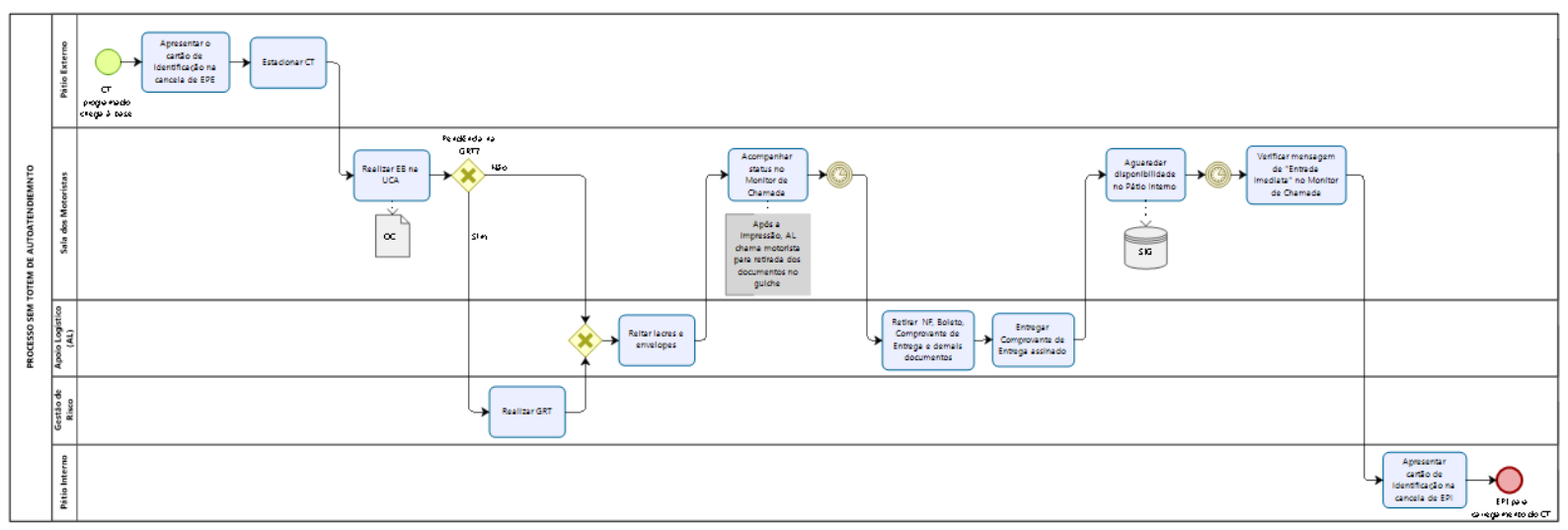

Fonte: Autores (2020)

\subsection{Autoatendimento}

Face a possibilidade de automatização e digitalização dos processos executados antes do caminhão-tanque (CT) entrar no pátio interno para carregamento, há a oportunidade de modernização e otimização do processo de atendimento aos motoristas, através da instalação de totens de autoatendimento com telefone direto instalado (hotline), para melhorar a comunicação entre a base e seus clientes.

Como ganho adicional, há a oportunidade de redução de custos devido a retirada de atividades que atualmente são executadas pela equipe do apoio logístico e, consequentemente, redução do custo operacional da base. Além da possibilidade de ganhos em redução do tempo médio de permanência dos CT's nas bases, devido a agilidade no autoatendimento e ininterruptibilidade do serviço de faturamento.

Após implantação dos totens de autoatendimento, ao chegar à base, o motorista passará seu cartão de identificação no leitor ou digitará a placa, o código e sua senha. O segundo passo será selecionar a opção de carregamento e confirmar a programação. Após verificação da segurança do transporte, através do Sistema de Gerenciamento de Risco de Transporte (GRT), o próprio motorista registrará os envelopes, lacres e aguardará a impressão da nota fiscal e 
demais documentos no totem indicado pelo monitor de chamada, estando apto a ser chamado para o carregamento na base (EPI).

A automação desta atividade, permite aos motoristas autonomia no atendimento, com redução do tempo para sua entrada na base de distribuição, através de uma proposta inovadora e de mudança de cultura, como o sequenciamento demonstrado na Figura 6.

Figura 6 - Fluxograma do processo entre o EPE e o EPI, com totem de Autoatendimento

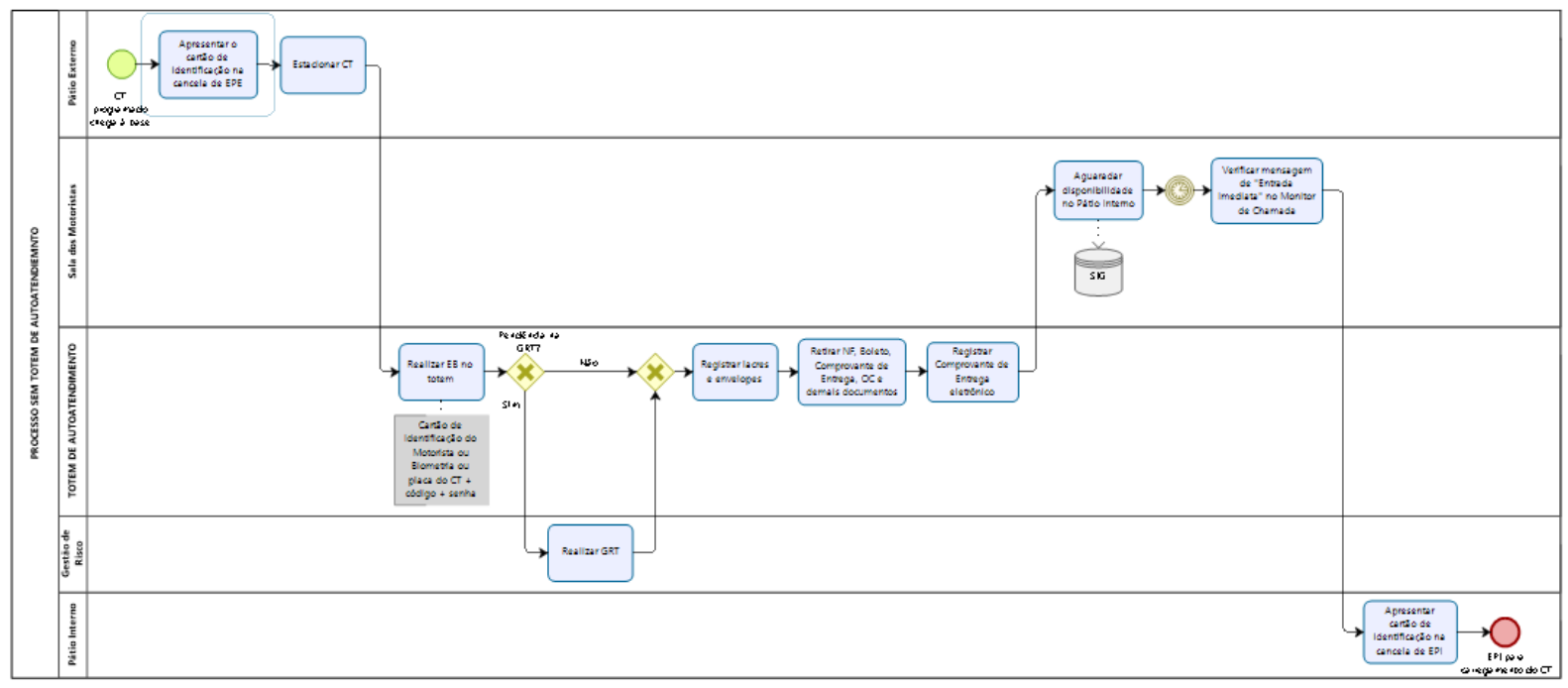

Fonte: Autores (2020)

O autoatendimento é uma solução integrada de hardware e software que permite o atendimento autônomo e independente dos motoristas que chegam na base. Porém, o maior gargalo desta solução é a escolha do melhor fornecedor para disponibilizar os totens que atendam aos requisitos de preço, prazo de pagamento, prazo de entrega, qualidade do produto (atendimento às especificações técnicas) e garantia (serviços pós venda).

\section{Resultados}

Foi realizado a pesquisa de mercado e identificados 3 fornecedores aptos a realizar a entrega dos totens nas bases. O Fornecedor 1 cobrou um preço de $\mathrm{R} \$ 494.850,00$ para o lote de totens solicitado, com prazo de entrega de 30 dias e prazo de pagamento também de 30 dias.

O Fornecedor 2 orçou um preço de $\mathrm{R} \$ 495.000,00$ para o mesmo lote, com prazo de entrega previsto para 60 dias e com prazo de pagamento de 20 dias. Já o Fornecedor 3 estimou o preço de venda em $\mathrm{R} \$ 497.700,00$ com 45 dias de entrega e prazo de pagamento em 30 dias. 
Os três fornecedores já comercializaram com a empresa antes e demonstraram aptidão técnica para atendimento do lote de totens previsto para instalação nas 41 bases, porém existe uma expectativa quanto ao nível de serviço esperado com relação à qualidade do produto e à garantia no serviço pós-venda, baseado em experiências passadas com os 3 fornecedores.

Os critérios selecionados foram aqueles utilizados no processo de aquisição da base e a equipe multidisciplinar de decisores foi composta por especialistas em cada uma das áreas afetadas pela implantação dos totens, sendo o responsável pela área de processos, o responsável pela automação e o responsável pela instalação, todos engenheiros e com vasta experiência profissional.

Para auxiliar no processo decisório de escolha do fornecedor, foi cadastrado o projeto “totem”, com o número 190 no SapevoWeb, conforme ilustrado na figura 7.

Figura 7 - Cadastro do projeto "totem" na ferramenta SapevoWeb

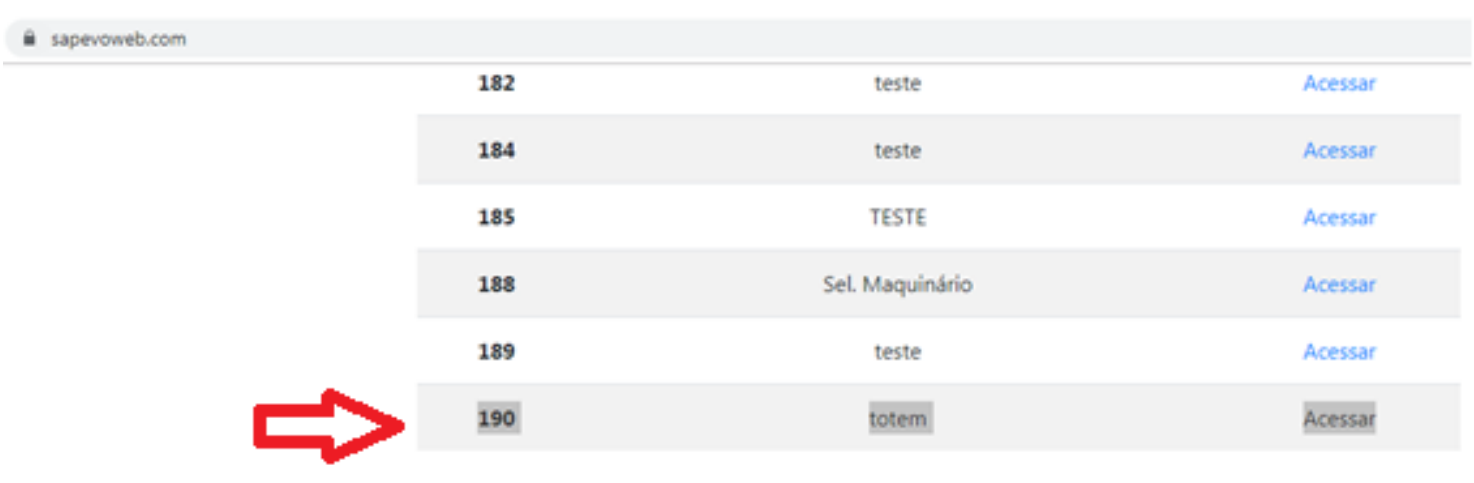

Fonte: Autores (2020)

Após o cadastro do projeto "totem" no sistema computacional SapevoWeb, foram registrados os 3 decisores (Área de Processos, Automação e Instalação) e os 3 fornecedores habilitados como alternativas propostas (Fornecedor 1, Fornecedor 2 e Fornecedor 3).

Os critérios para a tomada de decisão neste problema, foram os mesmos utilizados pela base nos processos de compras de equipamentos de automação, e também foram cadastrados no SapevoWeb, conforme apresentado na Figura 9. 


\begin{tabular}{|cc|}
\hline & Criterios \\
\hline$\#$ & Criterios \\
\hline $\mathbf{5 2 7}$ & Preço \\
\hline $\mathbf{5 2 8}$ & Prazo de pagamento \\
\hline $\mathbf{5 2 9}$ & Prazo de entrega \\
\hline $\mathbf{5 3 0}$ & Qualidade do produto \\
\hline $\mathbf{5 3 1}$ & Garantia (pós venda) \\
\hline
\end{tabular}

Fonte: Autores (2020)

Após o registro dos inputs, cada decisor preencheu sua percepção com relação à comparação entre os fornecedores, para cada um dos critérios, conforme indicado na Figura 9.

Figura 9 - Comparação entre as alternativas para cada critério

\begin{tabular}{|c|c|c|c|c|c|c|}
\hline \multicolumn{7}{|c|}{ Fornecedor 1 VS Fornecedor 2} \\
\hline Absolutamente Pior & Muito Pior & Pior & Equivalente & Melhor & Muito melhor & Absolutamente melhor \\
\hline \multicolumn{7}{|c|}{ Fornecedor 1 VS Fornecedor 3} \\
\hline Absolutamente Pior & Muito Pior & Pior & Equivalente & Melhor & Muito melhor & Absolutamente melhor \\
\hline \multicolumn{7}{|c|}{ Fornecedor 2 VS Fornecedor 3} \\
\hline Absolutamente Pior & Muito Pior & Pior & Equivalente & Melhor & Muito melhor & Absolutamente melhor \\
\hline
\end{tabular}

Fonte: Autores (2020)

Cada decisor também preencheu separadamente o nível de preferência entre os pares de critérios, baseado nas informações recebidas pelos fornecedores e experiências passadas com os mesmos, para geração dos pesos dos critérios, conforme demonstrado na Figura 10. 
Figura 10 - Combinações de comparações entre critérios

\begin{tabular}{|c|c|c|c|c|c|c|}
\hline \multicolumn{7}{|c|}{ Preço VS Prazo de pagamento } \\
\hline Absolutamente Pior & Muito Pior & Pior & Equivalente & Melhor & Muito melhor & Absolutamente melhor \\
\hline \multicolumn{7}{|c|}{ Preço VS Prazo de entrega } \\
\hline Absolutamente Pior & Muito Pior & Pior & Equivalente & Melhor & Muito melhor & Absolutamente melhor \\
\hline \multicolumn{7}{|c|}{ Preço VS Qualidade do produto } \\
\hline Absolutamente Pior & Muito Pior & Pior & Equivalente & Melhor & Muito melhor & Absolutamente melhor \\
\hline \multicolumn{7}{|c|}{ Preço VS Garantia (pós venda) } \\
\hline Absolutamente Pior & Muito Pior & Pior & Equivalente & Melhor & Muito melhor & Absolutamente melhor \\
\hline \multicolumn{7}{|c|}{ Prazo de pagamento VS Prazo de entrega } \\
\hline Absolutamente Pior & Muito Pior & Pior & Equivalente & Melhor & Muito melhor & Absolutamente melhor \\
\hline \multicolumn{7}{|c|}{ Prazo de pagamento VS Qualidade do produto } \\
\hline Absolutamente Pior & Muito Pior & Pior & Equivalente & Melhor & Muito melhor & Absolutamente melhor \\
\hline \multicolumn{7}{|c|}{ Prazo de pagamento VS Garantia (pós venda) } \\
\hline Absolutamente Pior & Muito Pior & Pior & Equivalente & Melhor & Muito melhor & Absolutamente melhor \\
\hline \multicolumn{7}{|c|}{ Prazo de entrega VS Qualidade do produto } \\
\hline Absolutamente Pior & Muito Pior & Pior & Equivalente & Melhor & Muito melhor & Absolutamente melhor \\
\hline \multicolumn{7}{|c|}{ Prazo de entrega VS Garantia (pós venda) } \\
\hline Absolutamente Pior & Muito Pior & Pior & Equivalente & Melhor & Muito melhor & Absolutamente melhor \\
\hline \multicolumn{7}{|c|}{ Qualidade do produto VS Garantia (pós venda) } \\
\hline Absolutamente Pior & Muito Pior & Pior & Equivalente & Melhor & Muito melhor & Absolutamente melhor \\
\hline
\end{tabular}

Fonte: Autores (2020)

\section{Discussão dos resultados}

Após inserir todos os dados de avaliação, a ferramenta SapevoWeb apresenta o resultado por ordem de prioridade, conforme demonstrado na Figura 11. 


\section{Resultado | Projeto totem Pesos \\ Critério - Preço - 2.909090909090909 \\ Critério - Prazo de pagamento - 0.009460539460539461 \\ Critério - Prazo de entrega - 1.4790209790209792 \\ Critério - Qualidade do produto - 2.10989010989011 \\ Critério - Garantia (pós venda) - 1.036963036963037}

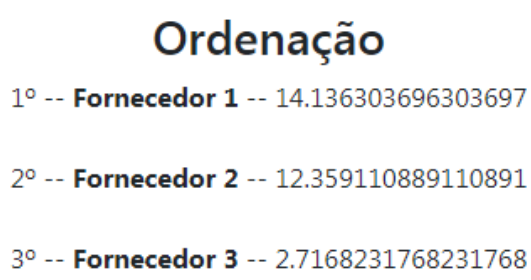

Fonte: Autores (2020)

Sendo assim, com a apresentação dos resultados para os Decisores, chegou-se à conclusão de que o Fornecedor 1, foi escolhido para prover totens de autoatendimento nas bases de distribuição de combustíveis.

\section{Conclusão}

Pode-se observar que o critério preço teve maior peso pelo decisores, seguido da qualidade do produto, o que fez com que os fornecedores 1 e 2 tivessem maior vantagem sobre o fornecedor 3, pois já teve experiências ruins com relação à qualidade e garantia no passado. $\mathrm{O}$ critério prazo de pagamento, embora seja considerado no procedimento corporativo da base, não foi muito importante para os decisores, pois ficou com o menor peso.

A partir da análise do ranking gerado pelo SapevoWeb, tem-se que o fornecedor 1 é a primeira alternativa para aquisição dos totens e foi a utilizada pelas bases, porém a ferramenta nos permite identificar o quão distante as alternativas estão entre si, sendo o fornecedor 2 bem próximo e o fornecedor 3 muito distante, podendo este ser descartado do processo decisório. Logo, está comprovada a eficiência desta ferramenta para aplicação do método SAPEVO-M para tomada de decisão envolvendo vários critérios e decisores. 


\section{REFERÊNCIAS}

AGÊNCIA NACIONAL DE PETRÓLEO, GÁS NATURAL E BIOCOMBUSTÍVEIS. Armazenamento e movimentação de produtos líquidos. Disponível em <http://www.anp.gov.br>. Acesso em 03 dez 2019.

ASSOCIAÇÃO NACIONAL DAS DISTRIBUIDORAS DE COMBUSTÍVEIS, LUBRIFICANTES, LOGÍSTICA E CONVENIÊNCIA (PLURAL). Mercado Revendedor. Disponível em <https://somosplural.com.br>. Acesso em 04 dez 2019.

CAITANO, Ana Lívia Alves; SANTOS, Marcos dos; GOMES, Carlos Francisco Simões; TENÓRIO, Fabrício Maione. Aplicação do Método THOR para escolha de um modelo de treinamento em um laboratório de metrologia. Anais XIX Simpósio de Pesquisa

Operacional e Logística da Marinha. Rio de Janeiro/RJ, 2019.

CARDOSO, L. C. S. Logística do Petróleo: Transporte e Armazenagem. Rio de Janeiro: Interciência, 2004.

GOMES, L. F. A. M.; GOMES, C. F. S. Princípios e métodos para a tomada de decisão: Enfoque multicritério. 6a ed. São Paulo: Atlas. 2019.

GOMES, L. F. A. M.; GONZALEZ-ARAYA, M. C. \& CARIGNANO, C. Tomada de decisões em cenários complexos. Rio de Janeiro: Pioneira Thompson Learning. 2004.

GOMES, L. F. A. M.; MURY, A. R.; GOMES, C. F. S. Multicriteria ranking with ordinal data. Systems Analysis Modelling Simulation. SAMS v.27, p. 139-146, 1997.

GRECO, S.; FIGUEIRA, J.; EHRGOTT, M. Multiple criteria decision analysis. New York: Springer, 2016.

OLIVEIRA, L. S. M.; CORREIA, T. C. V. D.; MELLO, J. C. C. B. S. Métodos multicritério de auxílio à decisão aplicados à avaliação e aquisição de imóveis. Relatórios de Pesquisa em Engenharia de Produção, v.8, n.4, 2008.

PIZZOLATO, N.D.; Gandolpho, A.A. Técnicas de Otimização. Rio de Janeiro: LTC, 2009.

TEIXEIRA, L. F. H. S. B; SANTOS, Marcos dos; GOMES, Carlos Francisco Simões. Proposta e Implementação em Python do Método Simple Aggregation of Preferences Expressed by Ordinal Vectors - Multi Decision Makers: uma ferramenta web simples e intuitiva para Apoio à Decisão Multicritério. Anais XIX Simpósio de Pesquisa Operacional e Logística da Marinha. Rio de Janeiro/RJ, 2019.

TEIXEIRA, L. F. H. S. B.; SANTOS, Marcos dos; GOMES, Carlos Francisco Simões. SapevoWeb Software (v.1). (2018). Disponível em: <http://www.sapevoweb.com> Acesso em: 03/12/ 2019. 